\title{
Nodular bleeding lesion on the sole revealing a case of Kaposi's sarcoma
}

\section{Mohammed Chaouche, Younes Barbach, Abdellah Dah cherif, Salim Gallouj, Fatima Zahra Mernissi}

Department of Dermatology and Venereology, University Hospital Hassan II, Fez, Morocco

Corresponding author: Dr. Mohammed Chaouche, E-mail: medch11@hotmail.com

Sir,

Kaposi's sarcoma (KS) is a rare angioproliferative disorder of the vascular endothelium that occurs in people infected with human herpesvirus-8 [1]. Four primary epidemiologic subtypes are commonly described: classic, AIDS-related, African, and iatrogenic. In this article, we present a rare case of nodular KS in a HIV negative patient.

A 65-year old male, presented to the dermatology clinic with a progressively growing and occasionally bleeding lesion on the sole of his right foot. There was no history of trauma and he was otherwise healthy. The patient declared that these lesions were present for nearly 2 years and was only aware of the lesion when it began to bleed approximately four months before the consultation. On examination, a purplish nodule with clear-cut borders and central ulceration was seen (Fig. 1). No other similar lesions were seen elsewhere. Routine laboratory tests were all normal. The anti-HIV test was negative. Histological examination of the biopsy found proliferation of fusiform cells within the dermis, which is associated with inflammatory infiltrate and many vessels. The patient's cells stained positive for human herpesvirus 8 , but was negative for melan A and HMB45.As the lesion was solitary, a surgical excision was performed.

Kaposi sarcoma is a vascular neoplastic disease caused by human herpesvirus 8 infection. Four variants of Kaposi sarcoma have been described, which present with similar cutaneous lesions that vary depending on clinical variant - pink patches to violet plaques in early stages, to nodules or tumoural polyps in later stages [2]. Lesions can be solitary or multiple.

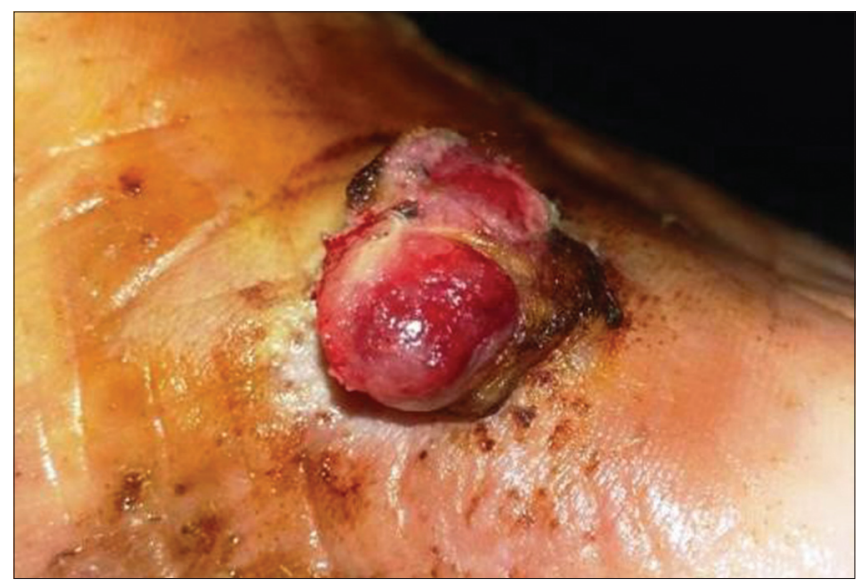

Figure 1: Nodular bleeding lesion on the sole.

The four variants differ mainly on the epidemiological aspects and are: African endemic Kaposi sarcoma, Kaposi sarcoma associated with iatrogenic immunosuppression, acquired immune deficiency syndrome (AIDS)-related epidemic Kaposi sarcoma, and classic Kaposi sarcoma, which appears in patients typically after the fifth decade and mainly in males of Mediterranean or Eastern European origin. Classic Kaposi sarcoma presents as slow-growing, red-violet macules on the distal lower extremities that can coalesce to form large plaques, develop into nodules, or even regress spontaneously. Sometimes, nodules are the first clinical observation since macules and plaques are asymptomatic.

In classic Kaposi sarcoma, which mainly affects immunocompetent patients and typically has a chronic and protracted course, achieving a complete cure might be unrealistic given the frequency of recurrence [3]. For the treatment of solitary lesions, surgical approach or radiotherapy are

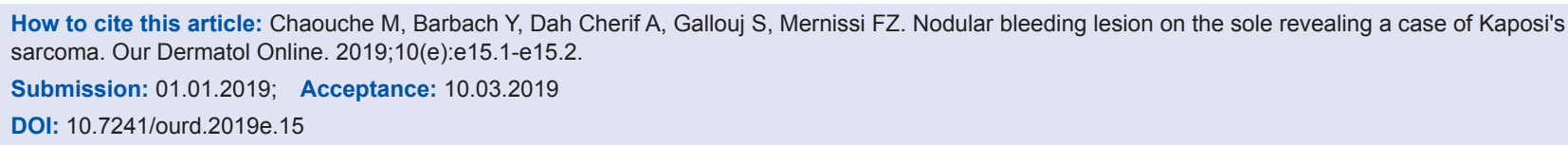


the preferred options. When multiple lesions are encountered, observation and close follow-up might be an option. Only rapidly progressive (more than 10 or more new cutaneous lesions in a month) or symptomatic visceral involvement require systemic chemotherapy [4].

\section{CONCLUSION}

In conclusion, classical KS is generally observed in the lower extremities as multiple lesions while isolated nodular sole lesion has rarely been seen.

\section{Consent}

The examination of the patient was conducted according to the Declaration of Helsinki principles.

\section{REFERENCES}

1. Antman K, Chang Y. Kaposi's sarcoma. N Engl J Med. 2000;342:1027-38.

2. Wu XJ, Pu XM, Kang XJ, Halifu Y, An CX, Zhang DZ, et al. One hundred and five Kaposi sarcoma patients: A clinical study in Xinjiang, Northwest of China. J Eur Acad Dermatol Venereol. 2014;28:1545-52.

3. North P, Kincannon J. Vascular neoplasms and neoplasticlike proliferations. In: Bologna J, Jorizzo J, Schaffer J, editors. Dermatology. Philadelphia, PA: Elsevier Saunders, 2012; p. 1937-39.

4. Mendez JC, Procop GW, Espy MJ, Paya CV, Smith TF. Detection and semiquantitative analysis of human herpes virus 8 DNA in specimens from patients with Kaposi's sarcoma. J Clin Microbiol. 1998;36:2220-22.

Copyright by Mohammed Chaouche, et al. This is an open-access article distributed under the terms of the Creative Commons Attribution License, which permits unrestricted use, distribution, and reproduction in any

medium, provided the original author and source are credited.

Source of Support: Nil, Conflict of Interest: None declared. 